\title{
Personajes Secundarios Sembrando Un Bonsái Relatos Minúsculos De La Historia Y La Memoria En La Narrativa De Alejandro Zambra*
}

\author{
Daniuska González González**
}

\section{Resumen}

Uno de los espacios recurrentes de la narrativa latinoamericana reciente es el acercamiento a la historia y la memoria desde la cotidianidad, algunas veces fragmentada, siempre fugaz, y a partir de la cual se enuncian, de perfil, los acontecimientos que, en algunas escrituras anteriores, se contaban con un registro épico. Desde esta perspectiva examinaré la narrativa de Alejandro Zambra (Santiago de Chile, 1975), enfatizando la construcción particular que realiza con los "personajes secundarios", categoría a la cual le coloca el peso del relato histórico y de la memoria desde sus existencias íntimas, diarias, intrascendentes.

Palabras clave: historia-memoria-personajes secundarios-literatura chilena-Zambra.

\section{Minor Characters Planting A Bonsai Minuscule Stories Of History And Memory In Alejandro Zambra's Narrative}

\begin{abstract}
A recurring subject in recent Latin American fiction is the approach to history and memory from everyday life, sometimes fragmented, always fleeting, and from which, events are uttered as a contour that, in some previous writings, were accounted for in an epic record. From this perspective, Alejandro Zambra's (Santiago de Chile, 1975) narrative will be analyzed, emphasizing the particular construction that is made from "minor characters", a category to which he places the weight of historical narrative and memory from their intimate, every day, frivolous existences.
\end{abstract}

Keywords: history-memory-supporting characters-Chilean literature- Zambra.

* Este artículo forma parte de la investigación en proceso "Los personajes fatales". Sujetos, personajes y derivas en la narrativa de los chilenos Roberto Bolaño, Alejandro Zambra y Diego Zúñiga y del colombiano Juan Gabriel Vásquez, que la autora realiza para el Centro de Estudios Avanzados (CEA) de la Universidad del Playa Ancha.

** Venezolana. Doctora en Humanidades de la Universidad Central de Venezuela. Investigadora del Centro de Estudios Avanzados (CEA) de la Universidad de Playa Ancha, Valparaíso, Chile. daniuska.gonzalez@upla.cl 
Estuvo bien ya de crecer,

es hora de desdibujarme,

lo que aprendí enhorabuena,

lo que olvidé también,

es hora de ser hijo de alguien

ya no me acuerdo qué buscaba, nadie recuerda lo que busca...

Fabio Morábito

\section{Los cuentos de los personajes. A modo de introducción}

Construir la narrativa desde las voces secundarias que dan cuenta del detalle, de la monotonía de vidas mediocres, en falta; y de la imaginación como resquicio frente a la memoria. Afincar retazos de los hechos en los cuales no repara el común de la gente; y hasta la historia ${ }^{1}$ se inserta como fragmento en la vorágine de la cotidianidad: un toque de queda en desarrollo se minimiza mientras transcurre el juego familiar sobre un tablero de Metrópolis.

Como si se plantara un bonsá i dentro del relato para verlo crecer: milimétrico y evocador, lento pero, al final, como un gran descubrimiento. Los cuidadores son los personajes secundarios²; ellos atraviesan la literatura de Alejandro Zambra (Santiago de Chile, 1975) y la pespuntean con sus pequeñas biografías privadas, sus inseguras y breves relaciones sentimentales y de familia, y hasta con la creación literaria, con lo cual encuadran la historia y la doblegan al antojo de la memoria. Como un fresco de época reducido, de una época minada por la contradicción, lo fugaz, la intemperie. Personajes secundarios cuidando un bonsái,

1 Con todo propósito, apunto historia con minúscula para insertarla en los hiatos, los silencios, los olvidos, puntos de fuga que Edward Said (2003) considera como lugares desde donde se escribe lo que algunos consideran la Historia (énfasis en la mayúscula). Asimismo, para Foucault (2000), "La historia será más 'efectiva' en la medida en que introduzca lo discontinuo en nuestro mismo ser. Divida nuestros sentimientos; dramatice nuestros instintos; multiplique nuestro cuerpo y lo oponga a sí mismo." (47); mientras que para Alain Brossat (2000), se trata de poner sobre escena las "anomalías" de la historia -precisamente los puntos de fuga para Said-, aquellas que sólo la figura del testigo puede relatar: “amnistías fallidas, [...] cómodas prescripciones, [...] consensuales pérdidas de memoria y la resignación a quedarse con aquellos saldos del pasado que sólo favorecen a los vencedores de la historia." (125).

2 "Personajes secundarios" se titula el Capítulo I de la novela Formas de volver a casa (2011) de este autor. 
mirando la lentitud menuda de la vida, su estéril verticalidad, mas definiéndola.

\section{La literatura (teórica) de los personajes secundarios}

No se puede trabajar la categoría de personaje sin detenerse en Mijaíl Bajtín, específicamente en algunos aspectos que aparecen en Estética de la creación verbal ([1979]1995) e iluminar desde allí las figuras secundarias de Zambra.

Bajtín se fija en el personaje central ${ }^{3}$ al que, en algunos momentos, valoriza como héroe y al que encarga el siluetaje de los otros, como los secundarios; desde el primero, éstos adquieren consistencia. De esta manera, todos se encuentran en constante diálogo entre ellos y con el autor, variables e imperfectos, originando "relaciones entre conciencias, verdades, influencias mutuas, aprendizaje, amor, odio, mentira, amistad, respeto, piedad, confianza, desconfianza, etcétera." (357). Además, en conjunto, crean las "voces enmarcadas", las cuales reúnen la experiencia de voces de contextos precedentes $\mathrm{y}$, a su vez, servirán como material para otras posteriores, futuras.

En principio, me afinco de estas ideas para señalar que, con escasas excepciones, la narrativa de Zambra se define a partir de los personajes secundarios, categoría que instituye el epicentro de sus relatos, la mirada que se instala cómodamente, sin compromiso, y elabora subjetividades.

$\mathrm{Al}$ respecto, dos premisas de Bajtín:

éste mostrará muchas muecas, facetas casuales, gestos falsos, acciones inesperadas relacionadas con las reacciones eventuales, caprichos emocionales y volitivos del autor, y este último tendrá que avanzar a través del caos hacia su verdadera postura valorativa, hasta que su visión del personaje llegue a constituir una totalidad estable y necesaria. Hay muchos velos que quitar de la cara de la persona más cercana, y según parece bien conocida (velos

3 Más acerca del personaje: su vida "es para el autor una vivencia dentro de las categorías valorativas muy diferentes a las de su propia vida y las de otras personas que viven a su lado y que participan de un modo real en el acontecer abierto, único y éticamente evaluable de la existencia; la vida de su personaje se llena de sentido en un contexto de valores absolutamente distinto." (Bajtín 24). 
que nuestras reacciones casuales, actitudes y situaciones cotidianas han aportado), para poder ver una imagen total y verdadera de esa persona. La lucha de un artista por una imagen definida y estable de su personaje es, mucho, una lucha consigo mismo. (16)

Comparto esta noción dúctil del personaje en tanto construcción donde el autor condensa una serie de características, entre éstas gestualidades, reacciones y emociones -y que, para Bajtín, nacen de estados del artista, lo cual triza, en esta cita específica, la autonomía del sujeto, propuesta ulterior de los estudios literarios-. De este segmento tomo un guijarro, el que alude al tramado con "muecas, facetas casuales, gestos falsos, acciones inesperadas"; insisto: lo desprenderé del contexto bajtiniano para desplegarlo sobre los personajes de Zambra, pues los observo relacionados con eventos que ponen en duda -históricos, sobre todo- $y$ con circunstancias de vida, evolucionando, de perfil, como bombas de racimo que se sueltan, desaparecen, se entrecruzan, deambulan...

Una segunda instancia posibilita una interpretación valiosa para mi objetivo: hay muchos velos que quitar de la cara. Ciertamente, como las capas de una cebolla, ir desnudando al personaje, encontrándole sus máscaras y lo que guarda detrás de cada una de éstas. Como cubierto con un jiyab, poco transparente sobre sí mismo -por eso su subalternidady, como en algunos momentos puede revelarse, insinúa elementos autobiográficos pero de difícil identificación para el lector, condenado a la suposición, a lo que Bajtín denomina "permanecer en la tangente" (366) de la voz del autor.

Como indica la cita, la cotidianidad se trasvasa de la categoría autor a la de personaje, este último aureolado por las contradicciones, las premuras, las añoranzas y las dificultades del primero; efectivamente, las recibe y engrasa el mecanismo narrativo -insinúo una semejanza con el punctum bartheano donde ocurre la identificación entre el objeto representado y el espectador-. Ese momento de aferrarse al personaje y con él "encamina[rnos] a un mundo de mierda... Un mundo donde es mejor ni siquiera pensar en el postre porque lo único que hay es una fuente inmensa repleta de nauseabundo arroz con leche." (Zambra, Mis documentos 137). Cuando, momentáneamente, podemos ser él. Cuando somos como él. 
A partir de Historia del nombrar. Dos episodios de la subjetividad (1990) de Carlos Thiebaut, cuestiono si se pueden trasvasar los términos de elaboración del sujeto moderno -que el autor lo desmembró a través de su representación pictórica- hacia los personajes secundarios de Zambra. Sobre todo porque interesan estos últimos como "un nuevo espacio de significaciones, [productores de] un nuevo texto" (121). Hago hincapié en lo último: tradicionalmente, esta identidad definitoria le corresponde al sujeto o al personaje central, no a los secundarios.

Ellos asumen una "atribución reflexiva e interpretativa" (Thiebaut 159), la cual los puede colmar "de rebeldías (negarse a ser quien me dicen ser), de imposibilidades o de desencuentros." (160). Más que personajes secundarios, se transforman en "sujetos secundarios", aunque, a criterio personal, implotan la clasificación: sus comportamientos dentro del relato desplazan al sujeto medular, sin ellos no puede comprenderse este escritor en ciernes o con cierto profesionalismo y quien hace del proceso creativo un depósito para guardar desde pensamientos (algunas veces inútiles) hasta breves conceptos sobre la cultura, la familia y la memoria.

Nada pasiva la mirada que imprimen. De ahí su novedad como "productores dentro del texto"; se han instalado en el medio de las narraciones y las acomodan trizando la noción del "texto que, como una cárcel, ahoga la vida y sus tareas" (Thiebaut 161). Racionales, cuidan sus pasos hasta abrir sus propios caminos o sus dubitaciones: "Me preguntan si soy el hijo de Manuel Contreras. Respondo que soy Manuel Contreras. Una vez tomé la guía de teléfonos y arranqué la página donde salía mi nombre, nuestro nombre. [...]. ¿Qué se siente no ser el hijo de uno de los mayores criminales de la historia de Chile? (Zambra, Facsímil 57); actúan $\mathrm{y}$, en consecuencia, le dan su lectura a lugares para reconocerse, para soportar crisis y carencias: "caminaba ensayando trayectos cada vez más largos, [...] el mundo no variaba demasiado" (Formas de volver a casa 22).

Parafraseando a Thiebaut, el relato de estos personajes secundarios no sólo es el "relato del yo", también deviene sumario de la construcción de un mundo, de sus interrelaciones recíprocas o excluyentes; un mundo al que puede socavar un terremoto, desestabilizar una relación de pareja, salvar un recuerdo familiar o descoyuntar una noticia histórica, y que, por supuesto, le posibilita al lector preguntarse por sí mismo y por su entorno. La ficción debe proponer tanto mundos de interrogantes como mundos de posibles "respuestas" y para esto debe servirle la voz de los 
sujetos (o los personajes). A contrapelo de De Man (1990) y de Barthes (1980, 1981 y 1994), sin desaparición del texto de donde éstos emergen, al contrario, afianzándolo.

Por otro lado, existe un aspecto que Tzvetan Todorov aborda en Los géneros del discurso (1996) que no puede dejarse al margen: las "constricciones concernientes al aspecto verbal del texto (...) y su aspecto semántico" (62), lo cual equivale a alternar "el discurso del narrador y el de los personajes" (Op. Cit.) con "la vida personal con preferencia, y no los grandes frescos de época" (Op. Cit.). Cierta la combinación en Zambra de lo que Todorov denomina aspecto verbal con las nimiedades, los acontecimientos banales y la actuación de los personajes, no con el objetivo de "asentar" una "verdad" de un periodo histórico o de crear una posición moral ${ }^{4}$, sino de acercarse de soslayo, desde el encuadre pequeño, familiar, afectivo.

Para Todorov, ese "continuum de hechos y relaciones" (71) marca el relato y condiciona que "la importancia del acontecimiento [sea] menor que la de la percepción o del grado de conocimiento que del mismo poseemos" (72). La época que pespuntea la narrativa de Zambra, bastante extensa porque sutura desde la dictadura hasta el presente democrático, se potencia no en los acontecimientos verídicos, algunos grandilocuentes (la imagen épica, entre el humo y las llamas, del Palacio de la Moneda bombardeado el 11 de septiembre de 1973), sino en el cómo se perciben, sobre todo por quienes los recuerdan y por quienes escuchan este recordatorio. Temporalidad más presentida, subjetiva, que real.

Los personajes secundarios: contundentes y, al mismo tiempo, en un segundo plano que no se les extraña cuando "parten"; como Ximena, la hermana de Claudia, en Formas de volver a casa, atrapada en un contraste: inquisitiva frente a la historia: "En ese tiempo la gente buscaba a personas, buscaba cuerpos de personas que habían desaparecido. Seguro que en esos años tú buscabas gatitos o perritos, igual que ahora" (91); indescifrable y codiciosa: "Estoy afuera, dice. Ximena me echó. Dice que la casa es suya. Que yo soy una extranjera y una puta." (110).

4 Hago coincidir una afirmación que sostuve cuando analicé la narrativa de Roberto Bolaño y que considero válida para Zambra: "No se puede dejar de subrayar que, contraponiéndose a Barthes, Bolaño estetiza una amoralidad de la escritura, una escritura que debe concebirse `sin afirmaciones ni negaciones, (...), sin pretensiones de guía, ni a favor ni en contra, (...) [que] no (...) juzga' (Bolaño, 2004: 79)" (González 177). 
Para Todorov “...la `verdad’ no existe sino bajo la forma de múltiples apariencias." (76): pienso desde aquí a las criaturas ficcionales de Zambra, responsables, como señala el autor, de "describir esos ruidos, esas manchas en la memoria. Esa selección arbitraria, nada más." (150-151).

\section{Una patada de risa a la historia. El Estadio Nacional: la vecindad chilena del "Chavo del 8"}

Formas de volver a casa ([2011]2012) constituye la propuesta narrativa más completa de Zambra. Terreno fértil para buscar interacciones individuales y colectivas de los personajes secundarios a las cuales interstician la fragilidad, la duda, la memoria. Sí, ellos se afincan en la historia y la interpretan, como una manera de jugar con ella, de disgregarla o compactarla, dependiendo de sus ilusiones o de sus pérdidas. Como "una tirada de dados que no abolirá el azar" del tiempo, de lo que sucedió y no puede cambiarse.

El niño, primer personaje secundario -disipado en la novela por quien instituirá más tarde la categoría de sujeto5: el escritor adulto-, revela “Una vez me perdí" (13) y le otorga uno de los sentidos al título. Duda de su edad, de la capacidad de sus padres para regresar a la casa (jcuando el perdido es él!), de su lentitud al caminar. Sin embargo, entre tropezones, como al voleo, arma un mapa de una etapa de la dictadura chilena con trozos mínimos y banales. Así, un terremoto unifica a la vecindad: "Encontré una silla de playa entre los escombros y me acerqué con timidez a la fogata de los adultos. Me parecía extraño ver a los vecinos, acaso por primera vez, reunidos. Pasaban el miedo con unos tragos de vino y miradas largas de complicidad. Alguien trajo una vieja mesa de madera y la puso al fuego..." (16).

No se aproxima por curiosidad, que sería lógico, sino por rechazo: había tratado de conversar con las niñas, reunidas en una carpa estilo iglú, y la hija del carabinero suelta una frase inquietante: “...me echó diciendo que quería violarlas." (16). Como sin pretender, se enquista una marca: época de dictadura, Carabineros, violación de derechos humanos.

5 Sujeto también como "Interrupción, quiebre, dislocamiento, un rayo que viene a perturbar el cielo sereno, figura crítica que busca su inspiración más allá de los confines de la modernidad." (Forster 139) (Lo destacado en negritas: D.G.). 
El pasaje se entrampa cuando introduce la siguiente observación: "En cuanto a Pinochet, para mí era un personaje de la televisión que conducía un programa sin horario fijo, y lo odiaba por eso, por las aburridas cadenas nacionales que interrumpían la programación en las mejores partes." (20-21). Le creo al autor cuando rotula este capítulo como "Personajes secundarios". Si me atengo a la categoría tradicional, este niño se inscribe en ésta, pero, en una vuelta de tuerca a Thiebaut y como renovación de Zambra, la hace menos rígida al potenciar el relato con su mirada entre inocente y perturbadora: a petición de Claudia, vigila a un vecino y se impone la entrega de un informe, en el cual "anotaría cada cosa que me pareciera sospechosa" (34) -agrego: un pequeño delator-, y esto es característico en Zambra.

Se trata, precisamente, de poner lo que cuesta enunciar sobre los hombros de los personajes secundarios: "Había cierto tipo de suciedad que simplemente yo no distinguía" (30), revela el niño. Estas palabras atraviesan la novela: ¿cuál suciedad? ¿Histórica? ¿Familiar? ¿De un paisaje urbano donde se superponen dictadura, desaparecidos, complicidad? Los personajes secundarios ensamblan las diferentes "formas de volver a casa": observan, dan traspiés y rememoran, sobre todo rememoran, que resulta la fórmula más compleja para hilvanar los diferentes sucesos y los tiempos de vida. Acaso, también, modos de no perderse.

Hay un punto grave que tensiona la historia con la normalidad y que la aplasta hasta escamotearla a través de la alegría:

Llegamos al Estadio Nacional. El mayor centro de detención en 1973 siempre fue, para mí, nada más que una cancha de fútbol. Mis primeros recuerdos son meramente deportivos y alegres. Seguro que también, en las graderías de ese estadio, tomé mis primeros helados.

El primer recuerdo de Claudia es también alegre. En 1977 se anunció que Chespirito, el comediante mexicano, vendría con todo el elenco de su programa para dar un espectáculo en el Estadio Nacional. Claudia tenía entonces cuatro años, veía el programa y le gustaba mucho.

Sus padres se negaron, en principio, a llevarla, pero al final cedieron. Fueron los cuatro y Claudia y Ximena lo pasaron muy bien. Muchos años más tarde Claudia supo que ese día 
había sido, para sus padres, un suplicio. Que cada minuto habían pensado en lo absurdo que era ver el estadio lleno de gente riendo. Que durante todo el espectáculo ellos habían pensado solamente, obsesivamente, en los muertos. (119-120)

Cuando se produce el golpe de estado en 1973, el Estadio Nacional ${ }^{6}$ se convirtió en un enorme campo de concentración donde se torturó y se asesinó, y donde rondaba una de las figuras más tenebrosas del periodo inicial de la represión: el encapuchado del Estadio Nacional6 . $\mathrm{Si}$ "la trama construye todos significativos a partir de acontecimientos dispersos." (White 68), la cita conjuga elementos triviales y los empalma para contraponerlos frente a lo hórrido del sitio: un helado, la infancia, una pelota que trae un pase futbolístico, la gracia de Chespirito... Dos niveles contraponiéndose en el referente Estadio Nacional: por un lado, como instalación para el disfrute artístico y deportivo; por el otro, como lugar marcado por el ultraje y la violación de los derechos humanos. Dos generaciones de personajes secundarios se yuxtaponen: una se identifica con una etapa oscura de la historia, con actos reales, como el atentado a Pinochet en 1986 (al respecto, lo abordaré más adelante, en un relato de Mis documentos); la otra con la televisión foránea, una generación "Chapulín Colorado" sin hazañas, más bien espectacularizada (Debord, 1967; Baudrillard, 1978, 1996).

A lo anterior se suma la risa, que fragmenta, pulveriza, como dice Barthes (1977), el acontecimiento histórico. Apenas tres años después de la existencia de este campo de concentración, sobre el cual testificó el investigador norteamericano Adam Scheisch que "La fila de la muerte entraba por un túnel del estadio y pasaban a la cancha de juego, donde serían ejecutados." (Montealegre 54), llegó el comediante mexicano Roberto Gómez Bolaños y en este espacio de

6 Según cuenta Jorge Montealegre en su imprescindible testimonio Frazadas del Estado Nacional (Santiago de Chile: LOM Editores, 2003): “En octubre de 1977, un hombre llamado Juan Muñoz Alarcón confesó en la Vicaría de la Solidaridad que él había sido el siniestro encapuchado. Se trataba de un antiguo militante socialista, que había sido expulsado de ese partido antes del golpe. Después -confiesa- 'fui llevado al Estadio Nacional para reconocer gente. Lo hice voluntariamente en ese entonces, porque en mí había un espíritu de revancha hacia los que habían sido mis antiguos compañeros, por la persecución de la que yo había sido objeto por parte de ellos: yo soy el encapuchado del Estado Nacional'. Más tarde recibió entrenamiento en Colonia Dignidad y fue colaborador de la DINA. Dejó una larga confesión y la certeza de que moriría pronto: 'Yo estoy muerto por uno de los dos lados'. Era la tragedia de un traidor que volvía a traicionar. El 24 de octubre de 1977 apareció asesinado en un potrero, con varias puñaladas y un balazo." (149). 
muerte y aniquilación desplegó su caracterización, lo cual produjo una borradura, un vaciamiento del "lugar de la memoria [que] se define por una red discursiva sumamente compleja, constituida por factores rituales..." (Huyssen 148). Una generación ríe mientras otra, la que le dio vida, rememora a sus muertos. ¿A qué apela esta contradicción? El segmento mayúsculo de la historia es aquél que se experimenta (los padres recuerdan) -"El momento de sobrevivir es el momento del poder" (Canetti 223)-, no el que le permite imaginar a los hijos.

Llama la atención que cuando ellos conversan sobre el Estadio Nacional, las palabras corren como al azar, carentes de sentimiento. Los asesinados pertenecen a otros, a quienes sabían lo que sucedía: "Todos estaban metidos en política, mamá." (Zambra 132). Hijos que le dan una patada a la historia, bien fuerte, para que el balón vuelva a las manos de Chespirito, ahora portero.

En el primer relato de Mis documentos, el cual le da título al libro, Dante, el niño autista, se hace voz entre los personajes secundarios para poner a flote fragmentos de la historia chilena reciente. No resulta casual que esta responsabilidad recaiga sobre un niño con esta condición. Por Foucault se sabe que los discursos -siempre interrumpidos, esquizoides, incompletos- que provienen de la locura, la enfermedad y los estados psicológicos especiales, operan como procedimientos de exclusión para razonar o, al menos, conseguir una posible "verdad"; sin embargo, incomodan y no tienen restricciones, circulan con la libertad de lo que no puede controlarse. "No se tiene derecho a decirlo todo, no se puede hablar de todo en cualquier circunstancia, [...]. Por las prohibiciones es que se revelan en el discurso las vinculaciones de éste con el deseo y con el poder." (El orden del discurso 12). La palabra de Dante (quien va creando un pequeño infierno a su alrededor, hasta generar temor) se erige como la manera más eficaz de narrar parte de la historia "en un mundo donde primaba el silencio y la desconfianza" (Zambra, Mis documentos 11).

7 Atentado que ocurrió en la cuesta Achupalla del camino al Cajón del Maipo y que organizaron miembros del Frente Patriótico Manuel Rodríguez (FPMR). Pinochet resultó ileso, no así cinco escoltas de su comitiva de seguridad. (Datos tomados de Escalante, Jorge; Guzmán, Nancy; Rebolledo, Javier; y Vega, Pedro. Los crímenes que estremecieron a Chile. Las memorias de La Nación para no olvidar. Santiago de Chile: CEIBO ediciones, 2013). Pedro Lemebel se basó en este hecho en su novela Tengo miedo torero (Barcelona: Seix Barral, 2001). 
En septiembre de 1986 sucedió el atentado a Augusto Pinochet ${ }^{7}$. Sin el niño autista, el hecho hubiera transcurrido sin sobresaltos en la zona capitalina del cuento, pero él "empezó a preguntarle a la gente de la villa si eran de izquierda o de derecha. Algunos vecinos reaccionaban incómodos, otros se reían y apuraban aún más el paso, otros le preguntaban qué entendía él por izquierda o por derecha. Pero no nos preguntaba a los niños, sólo a los adultos." (24-25).

La aparición de Dante se da como un destello, uno de los pocos que pretende una toma de posición política frente al acto; el niño autista desea potenciar una verdad y "dominar otra dimensión del discurso: aquélla de lo que acontece y del azar." (Foucault, El orden del... 21). Ante esto las reacciones oscilan en un espectro divergente: la risa, la incomodidad, fingir prisa, la pregunta como una evasiva... La negación. Nadie se atreve a definirse; inclusive, líneas más abajo, la voz narradora revela: "lo que quería era encajar, pertenecer, y si eran de izquierda yo también podía serlo, como también podía ser de derecha en la casa" (Zambra: Mis documentos 25).

Personajes secundarios como éstos se encuentran en los bordes de la historia y desde allí la narran; no se trata del sujeto militante de una organización armada convertida luego en torturadora (cf. La vida doble de Arturo Fontaine, 2010) o de un montonero preso quien busca, a toda costa, el silencio sobre sus acciones (cf. El beso de la mujer araña de Manuel Puig, 1976). Una nueva generación, la de los personajes secundarios, habla sobre la historia como si se refiriera a un acontecimiento en un domingo de paseo, y la desmonta a partir de sus fisuras, de su intimidad; de filigranas que proceden de lo cotidiano, de lo común. Con más fuerza, “...la narrativa configura el cuerpo de acontecimientos que constituyen su referente primario y transforma estos acontecimientos en sugerencias de pautas de significado que nunca podrían ser producidas por una representación literal de aquéllos en cuento hechos." (White 63).

Validando a White, el referente histórico en Zambra ocupa un segundo lugar, no el epicentro, y se difumina en función de lo conveniente a la imaginación y no al discurso que puede devenir crónica -"la narrativa sirve para transformar en una historia una lista de acontecimientos históricos que de otro modo serían sólo una crónica" (White 61)-. Por eso el regodeo, el gesto de desmontar metarelatos (o, mejor, de anularlos), 
de alejar cualquier asomo de grandilocuencia. La definición de historia es aquella que instauran los personajes secundarios: con una memoria reelaborada: "Godoy dictaba las dos horas enteras. Nos enseñaba la democracia ateniense dictando como se dicta en dictadura." (Zambra, Mis documentos 106); o con el gesto minúsculo de una niña: "Somos antiimperialistas, somos gente de izquierda, dice, y una sonrisa cómplice se esboza en la cara de Daniela." (La vida privada de los árboles 116).

De Facsimil rescato el ejercicio 64 de "IV. Eliminación de Oraciones", donde se produce una travesura perversa, una mascarada, un torbellino de identificaciones suplantadas alrededor de la figura de quien fuera, junto con Pinochet, el hombre más oscuro de la dictadura militar: Manuel Contreras, el director de la Dirección de Inteligencia Nacional (DINA) ${ }^{8}$. A través de una voz que dice llamarse así, mas voz de personaje secundario, tenue, casi en off, se forma la historia mediante el desmentido, la falsedad, la dubitación.

Me preguntan el nombre y respondo: Manuel Contreras. Me preguntan si soy Manuel Contreras. Respondo que sí. Me preguntan si soy el hijo de Manuel Contreras. Respondo que soy Manuel Contreras.

Una vez tomé la guía de teléfonos y arranqué la página donde salía mi nombre, nuestro nombre. Conté veintidós Manuel Contreras en Santiago. [...]. Pero después metí la hoja en la trituradora de papeles. Tener un nombre y un apellido comunes no me sirvió de nada. (56)

Este personaje parece permitirse un trasvasamiento de padre a hijo (más adelante se aventura a fondo con esta similitud); se busca en la guía telefónica ¿por simple placer? ¿Para diluir la mancha identitaria? ¿Acaso para compartir el peso del horror?, y, al final, sucede una operación absoluta de borramiento: la trituradora se traga todas las posibilidades de nombrarse, tanto aquélla libre de culpa como la del asesino. Como señalé sobre el texto de Thiebaut, estos personajes secundarios se apropian de las ventajas del sujeto, en este caso, en tanto "existencia única, autónoma, causas de lesa humanidad. Durante la dictadura fue el único director de la DINA y era considerado, luego de Pinochet, el hombre más poderoso del país. A él se le responsabiliza de numerosos crímenes emblemáticos, entre otros los asesinatos del general Carlos Prats y del ex canciller Orlando Letelier." (Rebolledo 23). 
autosuficiente, [que] no sería tal si [su] vida actual no estuviera también constantemente enraizada con el pasado, con [su] propio pasado." (Miras 242-243).

La pregunta regresa nuevamente:

¿Qué se siente ser el hijo de uno de los más grandes criminales de la historia de Chile? ¿Qué siente cuando piensa que su padre está condenado a más de trescientos años de cárcel? ¿Siente el odio de las familias que su padre destruyó?

[...] ¿Qué se siente no ser el hijo de uno de los mayores criminales de la historia de Chile? ¿Qué siente cuando piensa que su padre no asesinó a nadie, que no torturó a nadie?

Debo decir que mi padre es inocente. Debo decirlo. Tengo que decirlo. Estoy obligado a decirlo. Mi padre me va a matar si no digo que es inocente. Los hijos de asesinos no podemos matar al padre. (Zambra, Facsímil 57).

Ya no es Manuel Contreras sino su hijo (¿o no?). Este personaje secundario deambula entre el deseo y una hipotética realidad. Como una proyección fantasmática, en un limbo. ¿Quién se enuncia entonces: el hijo de un hombre común, inocente frente a la cronología histórica, o el de un criminal? Un secreto corroe esta voz, que quizá se disfraza, se escurre, para eludir responsabilidades, para separarse (aunque resulte vana tarea) del padre asesino, y, retomando a Miras, alza un impedimento que bloquea "el paso de los hechos -[...], en este caso, del crimen- hacia la conciencia." (243).

Más adelante, alguien ha tomado la voz del supuesto hijo para testimoniar la "verdad" desde la perspectiva de Contreras, el director de la DINA. Al primer ¿hijo? lo suplanta otro, igual de desconocido; como de una matrioska van saliendo hijos, uno dentro del otro, $\mathrm{y}$, al mismo tiempo, vuelven a introducirse en ésta. Y se instala un propósito: "Hacer saber 'como [sic] pasaron las cosas'" (Olea 214), el cual empuja "una política de la voz que al acusarse, [...] abre la pregunta por lo olvidado en su recuerdo." (Op. Cit.). 
La separación de rostros se vuelve un amasijo de complicidad, fingimiento, evocación... "Quizás cuando se publique el libro que el hijo de puta que finge mi voz está escribiendo..." (Zambra, Facsímil 58). La palabra escrita se potencia como el espacio desde donde expulsar los demonios de la historia, o, al menos, darle organicidad: habla el otro. De repente, un hijo (el lector ignora si el primero o el segundo) vuelve a transformarse en el padre: "Ahora está diciendo que doy órdenes, que sé torturar. [...]. Ahora está diciendo que yo digo que le perforen el ano con un chuzo." (Op. Cit.). ¿La escritura como el único lugar para cristalizar una identidad, por cierto, a través de un personaje secundario? ¿O desde el principio se trató de un engaño y siempre fue Manuel Contreras, el hombre duro de la dictadura, oculto detrás de duplicidades parentales? Un padre engendrando hijos que le niegan o le afirman indistintamente desde la mentira.

También en Facsímil, en el acápite "I. Término Excluido", se arma un puzle con una terminología abonada por la historia. Como un estudiante más, el lector se adentra en la Prueba de Aptitud Verbal, parte de la Prueba de Aptitud Académica en Chile hasta 2002, y uno de los ejercicios consistirá en marcar "la opción que corresponda a la palabra cuyo sentido no tenga relación ni con el enunciado ni con las demás palabras." (Zambra 13). Por ejemplo, "JUNTA: a) miedo b) cadáveres c) ganas d) agua e) monedas" (16). Él seleccionará a partir de su experiencia o, sobre todo, de su interpretación histórica. JUNTA militar del 11 de septiembre de 1973, que dio la orden de bombardear el Palacio de la Moneda (construido en la época colonial, entre 1786 y 1812, para acuñar monedas), que instauró el miedo y que llenó de cadáveres ${ }^{9}$ el país, muchos arrojados al mar (al agua). O “ALLANAR: a) nivelar b) recuperar c) investigar d) invadir e) aplastar" (17). Si enhebro un hilo desde este verbo hasta JUNTA puedo elaborar un pasaje histórico que pone sobre escena el acto de allanamiento como sinónimo de aplastar al enemigo político y de investigar, invadir y cancelar su vida.

A propósito, según su autor, "Éste es un libro contra la ilusión de una respuesta única, de una respuesta correcta y autoritaria" (Entrevista E12), también contra un único vínculo con la historia, sobre todo la oficial.

9 También puede ser un guiño a la novela Juntacadáveres (Primera edición 1949) de Juan Carlos Onetti, en la dirección de desmontar la instauración social de falsos valores. 


\section{4. "Meter la memoria en una bolsa [...] hasta que el peso le estropeara la espalda". Memoria y personajes secundarios}

...la memoria [es] invocada para que se constituya en un baluarte que nos defienda del miedo a que las cosas devengan obsoletas y desaparezcan, un baluarte que nos proteja de la profunda angustia que nos generan la velocidad del cambio y los horizontes de tiempo y espacio cada vez más estrechos. Andreas Huyssen, En busca del futuro perdido

Los personajes secundarios llevan sobre sus hombros el peso de la memoria, quizá la operación fundamental de reconstrucción social e individual. "Secundarios no tan secundarios", parecieran.

De un extremo al otro, una interrogante atraviesa la narrativa de Zambra: ¿quién guarda y puede relatar los recuerdos? Y agrego otra: ¿qué clase de recuerdos modelan el acontecimiento a capricho? La memoria: esa inestable e impracticable geografía, coincido con Guadalupe Santa Cruz (2000).

No existe pasado sin reconstrucción. Lo dejado atrás sólo puede volver como reinterpretación, como mirada que lo inquiere desde el presente. De esto se vale el escritor, lo aprovecha al máximo. Escritorescriba: quien transcribe al dictado pero filtra su propio trazado, su propia grafía, "el pasado como algo fracturado, fragmentado, distante, remoto y complejo" (Nora ctdo. en Lazzara 66).

Lo han planteado algunos teóricos: la escritura deviene proceso de restitución -no pienso negarlo-, sin embargo restituye engañosamente, por eso su condición de artificio. En uno de sus poemas más conocidos, "Caracas", Eugenio Montejo (Caracas, 1938-2008) establece un diálogo entre la ciudad real y la que rememora desde su niñez. Las coincidencias se extravían, huyen: Caracas, donde "Tan altos son los edificios" (101), se contrapone a la "sombra y [al] tacto de sus piedras, / ya no se ve nada de mi infancia." (Op. Cit.). No obstante, la ciudad se coloca como un texto que permite leer algunos de sus estratos; mas no pasará de ser un artificio poético, eso sí, con un registro particular: el poeta se siente partícipe 
tanto del ayer como del ahora, no está en suspenso, como quizá se infiera, sino que arma una pertenencia mixta, un reconocimiento de sí mismo en el presente que lo satura y en el pasado que lo calma. Como acota el narrador y poeta argentino Roberto Raschella, "no es un 'ir hacia' sino, de alguna manera, sentirse parte de eso" (Saraceni 203).

Interesa esta perspectiva para encarar a los personajes secundarios de Zambra, "ir quitándoles el velo" (Bajtín, 1995), ahora del recuerdo.

En el relato "Hacer memoria" de Mis documentos aparece la siguiente línea: "su trabajo consiste, también, en olvidar, o en fingir que recuerda lo que ha olvidado" (188). Tengo la certeza -realmente una de las pocas certezas frente a la narrativa de Zambra- que desde aquí arranca la aproximación al pasado: desde la dubitación, la incompletud, la triza. Responsabilidad de los personajes secundarios (ya de por sí una marca), la memoria resulta incompleta y, por tanto, defectuosa (aunque siempre lo es, toda vez que se realiza una operación de restitución a través de ella).

Esta memoria traza el espaciado de una zona de la ciudad de Santiago de Chile y semeja un calidoscopio, imágenes que se acoplan o se desestructuran de acuerdo con su grado de subalternidad a la rememoración:

Ahora Julián vive cerca de una calle celeste, Tobalaba, y antes vivió a pasos de una calle azul, Irarrázaval, frente a Plaza Ñuñoa, [...]. A esa casa llegó desde otras calles que no figuran en el Metrópolis, pues quedan lejos, hacia el poniente de la gran capital. Esas calles sin color alcanzan en la memoria un matiz grisáceo. Durante la infancia y la primera parte de la juventud de Julián esas calles fueron blancas. Sólo ahora son polvorientas. Sólo ahora, desde hace poco, el tiempo ha conseguido ensuciarlas. (73)

Geografía que se escrituriza desde el color. Recordar: acto cromático, como si un niño coloreara sobre un cuaderno estas calles que el presente invoca. ¿Acaso lo guardado adquiere "un matiz grisáceo", una tonalidad entre el blanco y el negro, entre el pasado irrecuperable y el presente que sólo puede devolverse a medias? La avanzada del tiempo (Arfuch, 2002) tiñe la remembranza pero a su modo. La memoria dibuja a capricho la ciudad de la infancia, la deslava: del blanco al gris, de lo puro a lo 
manchado; además, todo deslave arrastra escombros, fragmentos, objetos mutilados, basura: las calles limpias se contaminan y este contagio ocurre en la memoria. Como si recordar se convirtiera en un acto infeccioso.

Que pasa de una narrativa a la otra. En Formas de volver a casa, la penumbra adultera lo que se pretende recordar, se tilda de "trampa" (Zambra 62). Vuelta al gris, a la imposibilidad "de lo que todavía es y de lo que ya no es" (Richard 166):

Dondequiera que mire hay alguien renovando votos con el pasado. [...].

Me asombra la facilidad con que olvidamos lo que sentíamos, lo que queríamos. La rapidez con que asumimos que ahora deseamos o sentimos algo distinto. [...]. Queremos, creemos ser de nuevo los niños bendecidos por la penumbra.

[...]. Ayer escribí la escena del reencuentro, casi veinte años después. Me gustó el resultado, pero a veces pienso que los personajes no deberían volver a verse. Que deberían pasar de largo muchas veces, caminar por las mismas calles, acaso hablar sin reconocerse, de un lado al otro del mostrador.

¿Realmente reconocemos a alguien veinte años después? ¿Reconocemos ahora, a partir de un indicio luminoso, los rasgos definitivos, irremediablemente adultos, de una cara remota? (62-63)

No sobreviene consignación que traiga al pasado; no, al menos, como se vivió, mas, ¿se pretende? De ahí la falta de totalización de la memoria, su imposibilidad de cierre. Los personajes secundarios toman conciencia de esto y lo asumen como una estafa: lo odiado ayer, puede extrañarse hoy. Las calles de la ciudad quedan entre los colores que imponen los recuerdos; la niñez se bendice por la penumbra, por la opacidad de lo que luego se patentiza como una farsa. En la memoria se hace lugar el desencuentro, anida lo que se reconstruye, que ya no puede tocar el acontecimiento literal, la lealtad hacia su constitución. El tiempo se detiene pero deshelándose, uno y también otro. La memoria "entendida [...] como un proceso en-el-tiempo que se redefine desde y a través del presente, abierto a nuevas lecturas e interpretaciones capaces de revelar otras concepciones del pasado" (Saraceni 25). 
No he salido del círculo de lo minúsculo, de lo cotidiano. Avenidas, pasajes capitalinos, gestos, emociones, gente que entra y rápidamente se pierde: de ellos se nutre la memoria, en realidad, memoria del afecto, subordinada a parajes y sujetos reconocibles, íntimos, poco extraños.

La narrativa de Zambra se rodea de un mundo identificable, próximo; de aquello que, por cercano, se puede palpar, escuchar, olfatear, pensar: la iniciación sexual: "Todos los hombres de la familia habían pasado por Isidora, una mujer aún joven, [...], que accedía a atenderlos, aunque ya no era lo que se dice una puta, [...], trabajaba como secretaria de un abogado." (Bonsái s/p); la familia, problemática pero nunca olvidada: "la madre rasguea, con trabajosa exactitud, una canción de Violeta Parra." (La vida privada de los árboles 78) o "Vamos a fumar aquí dentro, aunque a tu papá no le guste" (Formas de volver a casa 134); las relaciones de pareja: “Ella no sabía qué hacer. Fue a la cama, lo abrazó, intentó dormir a su lado, pero no pudo. Prendió el computador" (Mis documentos 61); la música: "Así que escuchaba marchas militares todo el día, podría decir que esa fue la música de mi niñez." (12); el fútbol: "estoy hablando de fútbol con el padre de Camilo y siento una especie de estremecimiento." (47); el colegio: "El comportamiento del 34 contradecía por completo la conducta natural de los repitentes. (...) no era rencoroso." (100-101)... Rememoración que se basa en el decibel menor, trivial.

En Miedo líquido. La sociedad contemporánea y sus temores (2010), Zygmunt Bauman expone que uno de los temores mayúsculos que ha puesto en circulación la globalización está en el alejamiento de los paisajes, las sensaciones y las personas que pueden reconocerse y, por ende, el miedo se acumula frente al descontrol que produce esta extrañeza:

Tememos aquello que no podemos controlar. Llamamos 'incomprensión' a esa imposibilidad de control; cuando hablamos de la 'comprensión' de algo, nos referimos a nuestro conocimiento técnico sobre cómo abordarlo. Ese saber cómo manejar las cosas, esa comprensión, es un 'regalo' adjunto (o, mejor dicho, incorporado) a las herramientas capaces de llevar a cabo ese manejo. [...]. Si están ausentes las herramientas y las prácticas que éstas hacen posible, es harto improbable que ese conocimiento -o 'comprensión'- llegue nunca a producirse. La comprensión 
nace de la capacidad de manejo. Lo que no somos capaces de manejar nos es 'desconocido', y lo 'desconocido' nos asusta. Miedo es el otro nombre que damos a nuestra indefensión. (124)

Desde este razonamiento entiendo la memoria de los personajes secundarios como una herramienta, la eficaz herramienta que posibilita la sobrevivencia a través de la sutura de elementos que se interiorizan como cercanos. Modo que tienen para enraizarse y, como el bambú, dejarse torcer el tallo por el viento, mas no permitir su desprendimiento.

En la medida como puedan manejarse en un círculo poco expuesto a la extrañeza, reducen el desasosiego o, al menos, lo limitan a situaciones controlables: el término de un vínculo afectivo (Karla en La vida privada de los árboles); la propuesta de una mejora económica (Juan Emilio en el cuento "Larga distancia" de Mis documentos); el desafío de concluir una novela (la hermana que investiga por los personajes en Formas de volver a casa).

Pequeñas piezas sólo molestas, incapaces de abrir boquetes por donde pueda penetrar lo desconocido y con él, el miedo al que alude Bauman; "escenas de los personajes secundarios. Escenas razonablemente descartadas, innecesarias, que sin embargo coleccionamos incesantemente." (Zambra, Formas de volver a casa 122).

Mientras escribía, volví sobre el texto de Roberto Bolaño "Los personajes fatales", recogido en Entre paréntesis (2004) y el cual aborda la fotografía. Concluyo este acápite sobre la memoria minúscula, cotidiana, próxima que construyen los personajes secundarios de Zambra, con una idea del autor de Los detectives salvajes: cómo, a través del lente fotográfico, trata de detenerse en un hombre común, por ejemplo aquél "con bombín, abrigo y corbata [que] camina con la solemnidad de un astronauta." (264), tomado por casualidad, en una calle cualquiera de Londres, e ir tras sus pasos, su recorrido habitual. Amalgamarlo hasta crear un ser-prisma que dé paso a la luminosidad de lo cotidiano, de lo que luego constituirá, en un futuro próximo, la pequeña memoria de las cosas, no por pequeña menos vital, al contrario, imprescindible; esos "instantes irremediables que pasado un tiempo llamaremos vida" (Op. Cit.). 


\section{Hacer memoria. A modo de cierre}

A partir de la categoría de personajes secundarios, intenté una lectura a la narrativa de Alejandro Zambra (Bonsái, 2006; La vida privada de los árboles, 2007; Formas de volver a casa, 2011; Mis documentos, 2014; y Facsímil, 2014); a esos momentos que entrelazan la existencia cotidiana con la historia; que lo juntan con el devenir de "una familia que espera el toque de queda jugando al Metrópolis" (La vida privada de los árboles 71); con un ojo infantil que observa a Pinochet, al dictador, como "un personaje de la televisión que conducía un programa sin horario fijo" (21). Desde aquí reflexiono acerca del entramado de la historia como un mosaico pegado con miradas, recuerdos y gestualidades de la cotidianidad y alejado, por supuesto, de relatos totalizadores.

Por eso no hay voz del vencedor ni del vencido en los textos de Zambra, sólo la de estos personajes secundarios que hilvanan la historia y la memoria con sus emociones y sus desencuentros. Para ellos, historia mínima e íntima, arrugada por una "memoria metida dentro de una bolsa". Una historia frente al cual no interesa el ramaje, lo grandilocuente que se ve, sino el lugar bajo la tierra donde puede hurgarse hasta salir el brote, lo más importante: la raíz. Historia "bonsái", a veces tan pequeña, tan aparentemente nula, pero siempre firme, ligamento que sostiene "la vida privada" del recuerdo, y, con éste, la de nosotros, todos. 


\section{Referencias Bibliográficas}

Arfuch, Leonor. El espaciobiográfico. Dilemas de la subjetividad contemporánea. Buenos Aires: Fondo de Cultura Económica de Argentina, 2002.

Bajtín, Mijaíl. Estética de la creación verbal. México: Siglo XXI editores, 1979-1995.

Barthes, Roland. Sade, Loyola, Fourier. Caracas: Monte Ávila Editores, 1977.

. El grado cero de la escritura. México: Siglo XXI Editores, 1980. . Crítica y Verdad. México: siglo XXI Editores, 1981.

. El susurro del lenguaje (Más allá de la palabra y la escritura). Barcelona: Paidós, 1994.

Baudrillard, Jean. Cultura y simulacro. Barcelona: Kairós, 1978-1987.

. El complot del arte. Ilusión y desilusión estéticas. Buenos Aires: Amorrortu/Editores, 1996-2007.

Bauman, Zygmunt. Miedo líquido. La sociedad contemporánea y sus temores. Madrid: Espasa, 2010.

Bolaño, Roberto. Entre paréntesis. Barcelona: Anagrama, 2004.

Brossat, Alain. "El testigo, el historiador y el juez". Políticas y estéticas de la memoria. Ed. Nelly Richard. Santiago de Chile: Cuarto Propio. 123-133.

Canetti, Elías. Masa y poder. Barcelona: Muchnik, 1981.

Debord, Guy. La sociedad del espectáculo. Valencia: Pre-Textos, 1967-2002.

De Man, Paul. La resistencia a la teoría. Madrid: Visor, 1990.

Escalante, Jorge; Guzmán, Nancy; Rebolledo, Javier; y Vega, Pedro. Los crimenes que estremecieron a Chile. Las memorias de La Nación para no olvidar. Santiago de Chile: CEIBO ediciones, 2013.

Fontaine, Arturo. La vida doble. Barcelona: Tusquets, 2010. 
Forster, Ricardo. Walter Benjamin y el problema del mal. Buenos Aires: Altamira, 2001.

Foucault, Michel. El orden del discurso. Barcelona: Tusquets, 1987. . Nietzsche, la genealogía, la historia. Valencia, España: Pre-textos, 2000.

González, Daniuska. La escritura bárbara. La narrativa de Roberto Bolaño. Lima: Fondo Editorial Cultura Peruana, 2010.

Huyssen, Andreas. En busca del futuro perdido. Cultura y memoria en tiempos de globalización. México: Fondo de Cultura Económica, 2000.

Lazzara, Michael J. Prismas de la memoria: narración y trauma en la transición chilena. Santiago de Chile: Cuarto Propio, 2007.

Lemebel, Pedro. Tengo miedo torero. Barcelona: Seix Barral, 2001.

Miras, Pedro. “Testimonio, secreto, confesión". Políticas y estéticas de la memoria. Ed. Nelly Richard. Santiago de Chile: Cuarto Propio, 2000. 241-243.

Montealegre, Jorge. Frazadas del Estadio Nacional. Santiago de Chile: LOM Editores, 2003.

Montejo, Eugenio. “Caracas”. Antología. Caracas: Monte Ávila Editores, 1996. 101.

Olea, Raquel. "Yo Landa; abrir la memoria a otros relatos". Políticas y estéticas de la memoria. Ed. Nelly Richard. Santiago de Chile: Cuarto Propio, 2000. 213-220.

Onetti, Juan Carlos. Juntacadáveres. Bogotá: Oveja Negra Editores, 1964.

Puig, Manuel. El beso de la mujer araña. Barcelona: Seix Barral, 1976-2011. Rebolledo, Javier. La danza de los cuervos. El destino final de los detenidos desaparecidos. Santiago de Chile: CEIBO ediciones, 2013.

Richard, Nelly. "Imagen-recuerdo y borraduras". Políticas y estéticas de la memoria. Ed. Nelly Richard. Santiago de Chile: Cuarto Propio, 2000. 165-172. 
Said, Edward W. "El último bastión contra la barbarie". Le Monde diplomatique 15 (Septiembre 2003): 8-9.

Santa Cruz, Guadalupe. "Capitales del olvido". Políticas y estéticas de la memoria. Ed. Nelly Richard. Santiago de Chile: Cuarto Propio, 2000. 105-112.

Saraceni, Gina. Escribir hacia atrás. Herencia, lengua, memoria. Rosario. Argentina: Beatriz Viterbo Editora, 2008.

Thiebaut, Carlos. Historia del nombrar. Dos episodios de la subjetividad. Madrid: Visor, 1990.

Todorov, Tzvetan. Los géneros del discurso. Caracas: Monte Ávila Editores, 1996.

White, Hayden. El contenido de la forma: narrativa, discurso y representación histórica. Barcelona: Paidós, 1992.

Zambra, Alejandro. Bonsái. Barcelona: Anagrama, 2006.

- Entrevista. "Alejandro Zambra: 'Más que educados, fuimos entrenados'". Por Roberto Careaga. El Mercurio 30 Nov. 2014, Artes y Letras: E12.

. La vida privada de los árboles. Barcelona: Anagrama, 2007-2014a.

. Formas de volver a casa. Barcelona: Anagrama, 2011-2012.

. Mis documentos. Barcelona: Anagrama, 2014b.

. Facsímil. Santiago de Chile: Editorial Hueders, 2014c. 